\title{
Coping with a Lower Limb Amputation due to Vascular Disease in the Hospital, Rehabilitation, and Home Setting
}

\author{
Mélanie Couture, ${ }^{1}$ Johanne Desrosiers, ${ }^{2,3}$ and Chantal D. Caron ${ }^{2,3}$ \\ ${ }^{1}$ Centre de Recherche de the Institut Universitaire de Gériatrie de Montréal, Montreal, QC, Canada H3W 1W5 \\ ${ }^{2}$ Research Center on Aging, Sherbrooke University, Sherbrooke, QC, Canada J1H 4C4 \\ ${ }^{3}$ Faculty of Medicine and Health Sciences, Université de Sherbrooke, Sherbrooke, QC, Canada J1H 5N4
}

Correspondence should be addressed to Mélanie Couture, melanie.couture@umontreal.ca

Received 25 September 2012; Accepted 10 October 2012

Academic Editors: E. Goldhammer and J. D. Kingsley

Copyright (C) 2012 Mélanie Couture et al. This is an open access article distributed under the Creative Commons Attribution License, which permits unrestricted use, distribution, and reproduction in any medium, provided the original work is properly cited.

Objectives. To explore the coping strategies used following a lower limb amputation and their relationship to adjustment in the hospital, rehabilitation, and home setting. Method. Sixteen individuals who had a lower limb amputation due to vascular disease completed questionnaires, including the Ways of Coping Questionnaire (WCQ), during hospitalization (T1), at the end of rehabilitation (T2), and 2-3 months after discharge from rehabilitation (T3). A subsample $(n=10)$ also participated in three semistructured interviews analyzed using the approach of Miles and Huberman. Results. Self-controlling was the coping strategy used most, followed by seeking social support and positive reappraisal. Three additional coping strategies not found in the WCQ were identified in the qualitative data: noticing progress, learning new things, and using humor. Confrontive coping (T1) and escapeavoidance (T1, T2, and T3) were related to adjustment problems while positive reappraisal (T1 and T3), seeking social support (T1 and T3), and planful problem solving (T3) were associated with positive adjustment. Conclusion. Coping strategies used to deal with the amputation seem to vary across settings, thus signifying the complexity of the coping process following a lower limb amputation due to vascular disease.

\section{Introduction}

Following a lower limb amputation, many individuals face stressful situations such as phantom pain [1], loss of functional independence [2], and body image issues [3]. The coping abilities of individuals who had an amputation are greatly utilized and some may be overwhelmed by the task at hand. In fact, 15 to $42 \%$ of them develop depressive symptoms [4-9]. When facing a stressful situation, people react by using coping strategies, that is, they engage in multiple behavioral and cognitive efforts to regain or maintain their well-being [10]. Adjustment is the result of using various coping strategies to deal with the different stressful aspects of a situation, in this case, an amputation.

Coping strategies targeting emotions caused by a stressful event (emotion-focused strategies) have been found to be related to psychosocial and functional adjustment following a lower limb amputation. A study by Hill et al. [11] revealed that the combination of three coping strategies, namely, catastrophizing, increase in behavioral activities and hoping/ praying, accounted for a statistically significant proportion of functional $\left(R^{2}=0.12 ; P<0.001\right)$ and psychosocial $\left(R^{2}=0.19 ; P<0.001\right)$ adjustment problems even after controlling for demographic and amputation-related variables. Catastrophizing alone was a significant predictor of functional and psychosocial adjustment (11\% and $22 \%$ of the variance, resp.). Whyte and Carroll [12] also found that catastrophizing predicted $11 \%$ of the overall variance in disability, $6 \%$ of the variance in physical disability, and $13 \%$ of the variance in psychosocial disability after controlling for age, sex, duration of pain, and pain intensity $(P<0.0001)$ in 315 adults (20-60 years of age) who had an amputation. Cognitive disengagement [13] and avoidance strategies [14] have also been linked to higher levels of emotional distress.

Moreover, direct efforts to modify the situation (problem-focused strategies) have been linked to a more 
positive psychological adjustment following amputation. For instance, in a study by Desmond and MacLachlan [15], seeking social support was linked to lower levels of depressive symptoms and greater social adaptation, while problem solving was related to lower levels of psychological distress and anxiety. Livneh et al. [13] studied the coping strategies used by 61 individuals (mean $=55$ years) who had an amputation on average 16 years (range $=2$ months to 64 years) prior to the evaluation. Results showed that problemfocused strategies were related to fewer depressive symptoms, a greater acceptance of disabilities, and better adjustment to the amputation. However, a study by Gallagher and MacLachlan [14] with 44 individuals ( had an amputation on average 10 years (range $=2$ months to 60 years) prior to the evaluation revealed that problem solving and seeking social support were not related to psychosocial adjustment in terms of emotional distress.

These few studies that explored coping strategies and adjustment following an amputation had heterogeneous samples: many types of amputation (upper and lower limbs), different causes of amputation (disease, trauma, and congenital malformations), and various time intervals between amputation and measurement ( 2 months to 64 years). Therefore, with such results, it is difficult to pinpoint the population and timeframe for which these coping strategies are appropriate.

It is also important to determine not only which strategies are useful, but also in what particular context. The efficacy of a coping strategy is directly linked to the context in which it is used; a strategy may be appropriate in one context but not in another [16]. For instance, people often have to deal with three different settings within a few months of their amputation: the hospital, the rehabilitation unit, and home. This change in setting can hinder or facilitate the use of coping strategies and adjustment to the amputation.

More knowledge is needed before developing clinical interventions focusing on specific coping strategies. Consequently, the objective of the present study was to explore the relationship between coping strategies and adjustment following a lower limb amputation in terms of depressive symptoms, body image issues, and functional independence. To explore coping strategies in three different settings, data were collected during the first two weeks of hospitalization after surgery (T1), at the end of intensive rehabilitation (T2) and at home, that is, two to three months after discharge from rehabilitation (T3).

\section{Methods}

This is a descriptive study using a mixed-method design. The combination of a deductive and inductive process made it possible to identify coping strategies specific to the amputation experience that are not necessarily measured by questionnaires. In this study, quantitative data provided a general description of the sociodemographic and clinical characteristics of the participants, the global coping strategies they used to deal with the amputation, and their level of adjustment following the amputation (depressive symptoms, body image satisfaction, and functional independence). In addition, relationships between coping strategies and adjustment were explored. Individual interviews (qualitative data) were used to obtain the perspective of the participants regarding adjustment problems encountered following the amputation and how they learned to cope with them.

This study was approved by the Research Ethics Committees of the University Institute of Geriatrics of Sherbrooke and the Centre hospitalier universitaire de Sherbrooke. Written informed consent was obtained from the participants.

2.1. Participants. Sixteen participants who had an above- or below-knee unilateral amputation were recruited from a university hospital in Sherbrooke, Québec, Canada, and completed the study. Inclusion criteria were as follows: (a) 18 years or older, (b) above- or below-knee amputation for vascular reasons, (c) good cognitive functioning as measured by the Modified Mini-Mental State Examination (MMSE) [17] (>25th percentile according to age and schooling; see [18]), and (d) ability to understand written or spoken English or French.

Over the 36-month recruitment period, 36 patients were eligible to participate in the study. However, 14 patients refused to take part in the study and one was transferred to another hospital and could not participate. At the beginning of the study, 21 participants were evaluated during hospitalization (T1) but two refused to participate during rehabilitation (T2). Finally, two to three months after-discharge from rehabilitation (T3), another person refused to participate, one person was excluded after having the other leg amputated, and one person died. Thus, by the end of the study, a total of 16 participants had been evaluated at T1, T2, and T3. For the qualitative subsample, 10 individuals were interviewed at T1 and T2 and 8 at T3 (one died and another had a second leg amputated). Characteristics of the participants are presented in Table 1. Participants were comparable to individuals who refused on age and level of amputation. However, a greater number of men refused to participate $(P=$ $0.06)$.

2.2. Data Collection Procedure. The initial contact with individuals who had a lower limb amputation was made by a physical rehabilitation therapist who explained the general scope of the study. The names of those interested in the study were then given to the first author who contacted them for consent. The first author was also responsible for collecting all the quantitative and qualitative data. First, questionnaires were administered to the participants. Second, participants were invited to take part in recorded qualitative interviews lasting approximately one hour. If they agreed, they signed a second consent form. The maximum time interval between administration of the questionnaires and the qualitative interview was one week. The quantitative and qualitative data collection procedures were repeated at T2 and T3.

2.3. Quantitative Data Collection. Sociodemographic and clinical variables. Age, gender, schooling, and marital status 
TABle 1: Sociodemographic and clinical characteristics of the participants.

\begin{tabular}{|c|c|c|}
\hline & $\begin{array}{l}\text { Participants } \\
(n=16) \\
M(\mathrm{SD})\end{array}$ & $\begin{array}{l}\text { Qualitative subsample } \\
\qquad \begin{array}{c}n=10) \\
M(\mathrm{SD})\end{array}\end{array}$ \\
\hline Age (years) & $65.6(13.6)$ & $64.9(14.5)$ \\
\hline \multirow[t]{2}{*}{ Schooling (years) } & $10.1(3.3)$ & $9.6(3.4)$ \\
\hline & Frequency $(\%)$ & Frequency $(\%)$ \\
\hline \multicolumn{3}{|l|}{ Gender } \\
\hline Men & $9(56.3)$ & $6(60.0)$ \\
\hline \multicolumn{3}{|l|}{ Marital Status } \\
\hline Single & $3(18.8)$ & $2(20.0)$ \\
\hline Widowed & $3(18.8)$ & $4(40.0)$ \\
\hline Divorced/separated & $3(18.8)$ & $0(0.0)$ \\
\hline Married/common law & $7(43.8)$ & $4(40.0)$ \\
\hline \multicolumn{3}{|l|}{ Side of amputation } \\
\hline Right & $11(68.8)$ & $6(60.0)$ \\
\hline Left & $5(31.3)$ & $4(40.0)$ \\
\hline \multicolumn{3}{|l|}{ Level of amputation } \\
\hline Transtibial & $12(75.0)$ & $6(60.0)$ \\
\hline Transfemoral & $4(25.0)$ & $4(40.0)$ \\
\hline
\end{tabular}

were obtained from the participants. Level of the amputation, side of the amputation, cause of the amputation, and comorbidities were extracted from medical records.

2.3.1. Coping Strategies. The Ways of Coping Questionnaire (WCQ) was used to assess the thoughts and actions that people used to deal with their amputation [19]. Instructions to the participants were as follows and included a specific timeframe as recommended by the authors: "What was your attitude toward your amputation within the last week?" This instrument comprises 67 items scored on a four-point scale from 0 (not used) to 3 (used a great deal). Fifty of the items are grouped into eight subscales: confrontive coping (6 items), distancing (6 items), self-controlling (7 items), seeking social support (6 items), accepting responsibility (4 items), escape avoidance ( 8 items), planful problem solving (6 items), and positive reappraisal ( 7 items). To be able to compare the scores on each subscale, relative scores were calculated to control for the different numbers of items [20]. The Cronbach alpha coefficient for the eight subscales varies from 0.61 to 0.79 , indicating satisfactory internal consistency [19].

2.3.2. Depressive Symptoms. The Beck Depression Inventory (BDI) [21] was used to screen for 21 depressive symptoms (e.g., guilt, discouragement, feelings of failure, and dissatisfaction). Each item is scored on a four-point scale from 0 (no depressive value) to 3 (high depressive value). The final score ranges from 0 to 63 ( 0 to $9=$ absence of depressive symptoms, 10 to $18=$ mild to moderate depressive symptoms, 19 to $29=$ moderate to severe depressive symptoms, and 30 to $63=$ severe depressive symptoms). The total score has high internal consistency (Cronbach alpha coefficient of 0.91), high test-retest (Pearson coefficient $=0.90)$, and split-half $($ Spearman-Brown $=0.84)$ reliability $[22]$.

2.3.3. Body Image. The Body Image Questionnaire (BIQ) [23] evaluates perceptions, feelings, and attitudes a person has toward his/her own body. Each of the 19 items includes two adjectives at opposite ends of a continuum. The final score ranges from 19 (minimum) to 95 (maximum). A higher score reflects greater body image satisfaction. Testretest reliability obtained from a student population was 0.86 [24].

2.3.4. Functional Independence. The Functional Autonomy Measurement System (SMAF) [25] comprises 29 items evaluating functional independence on a five-point scale ranging from 0 (independent) to 3 (dependent). Five areas of functional ability are covered by the instrument: activities of daily living (ADL), mobility, communication, mental functions, and instrumental activities of daily living (IADL). The maximum score is 87 indicating a high level of dependency [25]. Test-retest and interrater reliability of the SMAF are very good (ICCs $=0.95$ and 0.96 , resp.) [26].

2.4. Quantitative Data Analysis. Depending on the continuous or categorical nature of the variables, mean and standard deviation or frequency and percentages were used to describe the sociodemographic and clinical characteristics of the participants. Because scores were not normally distributed, nonparametric tests were used. The Friedman test was used to compare coping strategies and adjustment variables across settings. Spearman's correlation coefficients were used to investigate the relationships between global coping strategies and adjustment variables. An alpha level of 0.05 was selected to determine the presence of significant relationships. SPSS 12.0 was used for all the statistical analyses.

2.5. Qualitative Data Collection. Qualitative interviews were used to get the participants' perspectives regarding adjustment problems related to the amputation and how they coped with those situations. Initial open-ended interview questions were developed by the three members of the research team:

(i) What are the negative changes in your life resulting from your amputation?

(ii) How do you deal with the changes we have just talked about?

(iii) What were the consequences of your efforts?

2.6. Qualitative Data Analysis. The first author transcribed the data and analyzed all the interview transcripts using the Miles and Huberman [27] analytical method. The qualitative data analysis was guided by the Transactional theory of stress and coping [28] and focused on identifying adjustment problems related to the amputation and the coping strategies they used to deal with those situations during hospitalization, rehabilitation, and after discharge 
from rehabilitation. Two procedures were used to analyze the data: codification and matrix building. First, codes were used to label units of text (words, sentences, and paragraphs) that encompass a distinct meaning. The coding list was based on the items of the Ways of Coping Questionnaire and was open to emerging coping strategies. Efforts were also made to code psychosocial and functional adjustment following the amputation.

As recommended by Miles and Huberman [27], the research process alternated between data collection and analysis in order to have the opportunity to recover missing information and to test new hypotheses developed during the analysis. Information collected at T1 and T2 and analyzed was checked with the participants in subsequent interviews. Interrater reliability was verified with a check-coding procedure. Two members of the research team coded parts of a $\mathrm{T} 1$ interview separately, and differences between the results were discussed and the codes modified accordingly. The same procedure was replicated with an external coder two-thirds into the analysis process with a T2 interview.

Second, matrices were used to further analyze patterns and relationships between codes. Data were displayed in time-ordered matrices to compare coping strategies across settings. A checklist matrix was built to identify the strategies used to adjust to depressive symptoms, body image issues, and loss of functional autonomy. Memos were written throughout the study to note theoretical and methodological decisions as well as hypotheses. The use of memos also facilitates the replication of the study and audit procedures.

\section{Results}

In this section, quantitative and qualitative data are used in a complementary manner. First, quantitative and qualitative data present a general portrait of the coping strategies used to deal with the amputation across settings. Second, both types of data are used to explore the relationship between coping strategies and adjustment in terms of depressive symptoms, body image satisfaction, and functional independence.

\subsection{Coping Strategies Used to Deal with the Lower Limb} Amputation. Quantitative results showed that the participants used an average of 30 different coping strategies at T1, T2, and T3. Self-controlling was used the most throughout the study, followed by seeking social support and positive reappraisal (see Table 2 ). There were statistically significant increases in the use of planful problem solving in the rehabilitation setting (T2) $(P<0.01)$ and the use of distancing in the home setting (T3) $(P<0.01)$.

In spite of the various coping strategies included in the Ways of Coping Questionnaire, three additional coping strategies associated with the amputation experience were identified in the analysis of the qualitative data: noticing progress, learning new things, and using humor. In the course of the study, many participants described efforts to notice the progress made since the amputation, as one participant explained: "From one day to the next, I notice I can do a lot more and that helps me a lot." Participants also made an effort to develop new knowledge and apply it to resolve stressful situations. For example, during rehabilitation (T2), many had to learn how to use assistive devices such as a walker: "You're not supposed to jump. You're supposed to keep your feet on the ground. I didn't know that." Efforts were also made to have fun and use humor despite the amputation. At T1 and T2, making jokes with other patients and health care professionals was also a way to take the drama out of the situation: "I was always in a good mood. I love to play tricks and tell jokes."

\subsection{Relationship between Coping Strategies and Adjustment.} In this section, results are organized according to adjustment in terms of depressive symptoms, body image satisfaction, and functional independence. For each adjustment variable, quantitative data are used to get a global idea of adjustment following a lower limb amputation and to describe statistical relationships between coping strategies and adjustment at T1, T2, and T3. Qualitative data help understand how individuals who had a lower limb amputation deal with adjustment problems at T1, T2, and T3.

3.2.1. Depressive Symptoms. Quantitative results showed that some people experienced depressive symptoms in the course of the study (see Table 3). During hospitalization (T1), three participants experienced mild depressive symptoms, one person had moderate to severe depressive symptoms, and another person had severe depressive symptoms. At T2, two individuals had mild depressive symptoms and at T3, five participants expressed mild depressive symptoms. Statistical results revealed a relationship between high depressive symptoms and the use of escape-avoidance $(R=0.747 ; P=0.001)$ at T1. During rehabilitation (T2), no coping strategies were statistically correlated with depressive symptoms, but very few individuals had depressive symptoms at that time. At T3, accepting responsibility for the amputation was related to more depressive symptoms $(R=0.541 ; P=0.031)$.

Qualitative data at T1 revealed that the emotions of sorrow and anger were present early on after the amputation, as one participant explained: "When I realized that my leg had been amputated, I cried. (...) I wanted to destroy everything around me. I was very bitter." To fight depressive symptoms during hospitalization (T1), people made cognitive efforts to look on the bright side of things: "You don't have a choice. If you look on the bad side of things, you'll get depressed. You have to find a way to smile." Using humor was also a way of dealing with negative emotions: "I try to find the funny side of the situation instead of always being disappointed." Some people talked to friends and family members about how they were feeling: "After the amputation, I talked to people about it. (...) Talking about it releases a lot of anxiety and stress." Some participants prayed to God instead of talking to people to release negative emotions: "The first few days, I was not aware that my leg was amputated. I was happy and OK. (...) It was a few days later that I started asking God what I was supposed to do now."

During rehabilitation (T2), some of the same coping strategies used during hospitalization remained: trying to 
TABLE 2: Relative mean score on The Ways of Coping Questionnaire across settings $(n=16)$.

\begin{tabular}{lcccc}
\hline Coping strategies & Hospitalization & Rehabilitation & After discharge & Friedman \\
& T1 & T2 & T3 & $\chi^{2}$ \\
\hline Self-controlling & 0.18 & 0.17 & 0.20 & 2.38 \\
Seeking social support & 0.15 & 0.14 & 0.13 & 0.31 \\
Positive reappraisal & 0.13 & 0.14 & 0.15 & 0.46 \\
Planful problem solving & 0.12 & 0.16 & 0.12 & 0.38 \\
Distancing & 0.12 & 0.13 & 0.18 & 9.46 \\
Confrontive coping & 0.11 & 0.08 & 0.09 & 9.50 \\
Escape-avoidance & 0.11 & 0.08 & 0.07 & $0.01^{* *}$ \\
Accepting responsibility & 0.08 & 0.10 & 0.07 & $0.01^{* *}$ \\
\hline
\end{tabular}

${ }^{*} P<0.05$ and ${ }^{* *} P<0.01$.

TABLE 3: Depressive symptoms, body image satisfaction, and functional independence across settings $(n=16)$.

\begin{tabular}{|c|c|c|c|c|c|}
\hline \multirow{2}{*}{ Measure } & \multirow{2}{*}{$\begin{array}{l}\text { Hospitalization } \mathrm{T} 1 \\
M(\mathrm{SD})\end{array}$} & \multirow{2}{*}{$\begin{array}{c}\text { Rehabilitation T2 } \\
M(\mathrm{SD})\end{array}$} & \multirow{2}{*}{$\begin{array}{c}\text { After discharge } \mathrm{T} 3 \\
M(\mathrm{SD})\end{array}$} & \multicolumn{2}{|c|}{ Friedman } \\
\hline & & & & $\chi^{2}$ & $P$ \\
\hline BDI & $9.1(9.5)$ & $5.9(3.7)$ & $6.4(4.4)$ & 0.85 & 0.66 \\
\hline BIQ & $69.7(12.4)$ & $70.9(10.9)$ & $67.4(10.6)$ & 1.68 & 0.43 \\
\hline \multicolumn{6}{|l|}{ SMAF } \\
\hline Mobility & $10.1(2.9)$ & $5.2(2.5)$ & $3.8(2.3)$ & 26.95 & $<0.01^{* *}$ \\
\hline $\mathrm{ADL}$ & $3.3(1.8)$ & $1.3(2.0)$ & $0.9(2.3)$ & 19.90 & $<0.01^{* *}$ \\
\hline IADL & $18.6(1.5)$ & $10.3(5.1)$ & $8.3(5.8)$ & 25.41 & $<0.01^{* *}$ \\
\hline
\end{tabular}

BDI: beck depression inventory; BIQ: body image questionnaire; SMAF: functional autonomy measurement system.

${ }^{*} P<0.05$ and ${ }^{* *} P<0.01$.

look on the bright side of things, talking to someone, praying and using humor. In addition, some coping strategies were specific to the rehabilitation phase. One of the participants redoubled his efforts to resist the temptation of staying home instead of going to rehabilitation: "Rehabilitation takes a lot of effort, not just physically but also psychologically." When feeling stressed out, one person decided to avoid being with people. Another participant took solace in faith: "I don't worry about life because I believe we have a destiny."

Once at home (T3), people apparently preferred to keep feelings hidden from others and refused to think about the amputation. For one participant, thinking about the amputation was difficult: "I'd rather not think about the amputation. (...) It makes me angry. I'm ready to blow up at any time."

Throughout the three different settings, one strategy was recurrent: when feelings of anger were overwhelming, some participants took it out on others. During hospitalization (T1), health care professionals were the prime target for releasing tension:

"The first week after the amputation, I was unapproachable. Once, my friend told me I was rough with the nurses. I told her that if she'd been in my shoes, she wouldn't have done any better. I did, however, promise not to do it again. (...) It was not normal for me to act like this because I'm not an aggressive person. I was at the end of my rope and I was in pain."

During rehabilitation (T2), one participant remembered taking it out on his spouse: "I found it difficult for our relationship because of what it imposes on the other person. We often take out our frustrations on those we love and are closest to us." Another participant reported that once she settled in at her new nursing home (T3), she got angry at other residents: "There is one resident who makes me so angry. He is always closing windows in the hallway and the games room. (...) I used to be more level-headed."

3.2.2. Body Image Satisfaction. Scores on the QIC range from 42 to 89 , indicating that some individuals have body image issues. According to the statistical analysis, participants using positive reappraisal at $\mathrm{T} 1$ had greater satisfaction with their body image $(r=0.737 ; P=0.002)$. There was no indication of any other coping strategies being correlated with body image satisfaction at the end of rehabilitation (T2). At T3, seeking social support was associated with greater body image satisfaction $(r=0.537 ; P=0.032)$.

Throughout the qualitative interviews, very few participants admitted that body image was a problem and only a small number of coping strategies to deal with body image issues were identified. At T1, two participants refused to think too much about their image and one had fantasies about how things might turn out: "Later on, I'll have a prosthetic limb and the problem will disappear." At T2, one participant went along with faith and two came up with an easy solution to hide the stump: "I wear pants when I go outside especially to a restaurant." Finally at T3, participants still refused to think too much about it and pants were used to hide the amputated limb or the prosthesis. 
3.2.3. Functional Independence. From the hospital (T1) to home (T3), participants significantly increased their level of functional independence, as seen in Table 3. During hospitalization (T1), accepting responsibility was linked to greater levels of independence in ADL $(r=-0.511 ; P=0.043)$ and seeking social support to greater levels of independence in IADL $(r=-0.770 ; P<0.001)$. However, the use of confrontive coping was associated with lower levels of independence in ADL at T1 $(r=0.672 ; P=0.004)$. No strategies were related to mobility on the SMAF scale.

At the end of rehabilitation (T2), escape-avoidance was associated with lower levels of functional independence in ADL $(r=0.598 ; P=.014)$, and IADL $(r=0.599 ; P=$ $0.014)$. No coping strategies were related to mobility on the SMAF scale. Finally at T3, people who used planful problem solving showed higher levels of independence in mobility $(r=-0.783 ; P<0.001)$, ADL $(r=-0.653 ; P=0.006)$ and IADL $(r=-0.717 ; P=0.002)$. Positive appraisal was also associated with higher levels of independence in ADL $(r=$ $-0.503 ; P=0.047)$. Greater use of escape-avoidance was related to lower levels of functional independence in mobility $(r=0.540 ; P=0.031)$ and ADL $(r=0.627 ; P=0.009)$.

Qualitative data revealed that during hospitalization (T1), participants dealt with their loss of functional independence by drawing on past experiences of hospitalization and by making an effort to notice the day-to-day progress they made. In the rehabilitation phase (T2), many doubled their efforts to get better by doing all the exercises that the therapist recommended and they also developed different solutions to improve their functional autonomy such as preparing things in the bathroom before taking a shower. Most of all, many realized it was important not to act too hastily when they moved around to avoid harm. Three strategies were utilized during hospitalization (T1) as well as rehabilitation (T2) to deal with the loss of functional independence: trying to look on the bright side of things, learning new things, and being inspired by another person. For example, one woman got her inspiration from a well-known wheelchair athlete: "She had a great challenge to overcome too and she succeeded. Also, she's always smiling. When I saw her doing interviews on television, I thought she had a lot of charisma. (...) It inspired me."

During rehabilitation (T2) and at home (T3), participants were ready to put a lot of effort into being able to use the prosthesis: "I did so many exercises to harden my leg. I never stopped." A few participants actually did something creative to accelerate their rehabilitation: they built a homemade prosthesis. "I could only wear the prosthetic limb when I was in the rehabilitation unit. I was a little disappointed but it was alright because I built a home-made version to use at home." Once at home (T3), 12 of the 16 participants had a prosthetic limb. All of these twelve participants said they would wear the prosthesis and put it on by themselves without any help. On average, participants wore their prosthesis six days a week for approximately ten hours per day. Nine participants confessed that they still needed to concentrate when they walked with the prosthesis and three of them actually fell. As one participant explained: "They say you have to look where you walk. (...) When there's an obstacle, you make your first step using your good leg. (...) You have to think about that."

One coping strategy was crucial for dealing with the loss of functional independence in all three settings: talking to someone who could do something about the situation. For some participants, getting help was perceived as a positive experience because it saved time and energy: "You can't imagine the difference it makes in my day. After doing everything by yourself for a whole day, you get really tired and burned out. With a little help (...) you do twice as much as you would normally do."

However, asking for help had many disadvantages according to the participants. First, asking for help meant that you had to disturb someone: "I don't like asking because I don't like to inconvenience people and everybody has something in their life they have to do. I don't like to interfere with their routine. Why should their routine be upset because mine is?" Second, by getting someone to help, the work might not be done properly: "Having someone work here gets on my nerves. On top of that, they don't do the work the same way I did." Third, when a person asks for help, she might face rejection: "You know the person will only help you if he or she wants to help." Finally, feelings of worthlessness can emerge after asking for help: "I feel belittled. (...) If I had my two legs, nobody would have to help me."

To avoid negative feelings caused by asking for help, a few participants resorted to other strategies during hospitalization and rehabilitation. At T1, one person explained why she avoided being with people in general: "You put a barrier between you and other people because you don't accept it [amputation]. All the others want is to help you accept it but you don't see it that way. It's like they're telling you: 'You're no good. You can't do that. That's why I'm helping you."' At $\mathrm{T} 1$ and T2, people also took risks or tried to convince other people that they did not need any help. For one individual, it was more important to do things by himself than to avoid physical harm: "I do things by myself as much as possible. I've made a fool of myself before and I'll surely do it again. Even if I fall and hit my head, at least I did it by myself." One person tried to convince the doctor she did not need any help by demonstrating her abilities: "I showed him. I said: 'Look, I don't need anyone to push [the wheelchair]."

In conclusion, the quantitative and qualitative results give an indication how individuals who had an amputation coped with depressive symptoms, body image issues, and loss in functional independence in hospital, rehabilitation, and home setting. Overall, confrontive coping (T1) and escapeavoidance (T1, T2, and T3) were related to adjustment problems while positive reappraisal (T1 and T3), seeking social support (T1 and T3), and planful problem solving (T3) were associated with positive adjustment.

\section{Discussion}

The general aim of this study was to explore how individuals deal with their lower limb amputation due to vascular disease in different settings. The diversity of the coping strategies used reflects the complexity of the adjustment process 
following an amputation. Participants used mainly coping strategies related to self-controlling, seeking social support, and problem solving. Interestingly, in the rehabilitation setting, there was an increase between $\mathrm{T} 1$ and $\mathrm{T} 2$ in the use of planful problem solving. This is consistent with rehabilitation where efforts focus on maximizing functional abilities and learning to use the prosthetic limb. This part of the adaptation process is mainly action-oriented and the person is acting upon the situation. Between T2 and T3, there was an increase in the use of distancing strategies. At that point, individuals are trying to detach themselves from the amputation. Sjödahl et al. [29] also noted that when returning home people find it difficult to see that small things have become harder to do such as using the stairs. In these conditions, emotion-focused strategies are relevant.

From the qualitative data standpoint, additional coping strategies were identified: noticing progress, learning new things, and using humor. To our knowledge, the first two strategies have not been discussed in any other amputation literature. This may be because most studies used questionnaires and very few are based on an inductive process to uncover coping strategies specific to lower limb amputations. In a grounded theory proposed by Oaksford et al. [30], humor was identified as a coping strategy to deal with disability within the first 6 months, one year, and five years following transtibial amputation. On the other hand, Rybarczyk, Nicholas, and Nyenhuis [31] conceptualized humor as a tool that facilitates coping but not as a coping strategy. In this study, using humor is considered a coping strategy because participants made a conscious effort to utilize humor to diminish their own negative emotions related to the amputation or those of family members and friends.

In regard to adjustment, rates of depressive symptoms in our sample $(31 \%)$ were within the range found in other populations of individuals who had an amputation [4-9]. Depressive symptoms were associated with escape-avoidance during hospitalization and accepting responsibility for the amputation after discharge from rehabilitation. Other studies [11-14] also reported that negative psychological adjustment is associated with emotion-focused coping.

As for body image satisfaction, quantitative results showed that participants had lower levels of satisfaction than other populations, such as patients with cancer. Indeed, satisfaction levels were relatively stable across settings, suggesting that people did not necessarily get used to the stump with time. However, during qualitative interviews, very few spoke about this issue or the coping strategies used to deal with it. Zidarov et al. [32] also noted in their study that body-image disturbances were absent during rehabilitation and at 3month followup. This raises the question of whether people were using denial. Nonetheless, qualitative data from our study include many examples of people who did not find their body image repulsive following the amputation. Many were able to look at and touch their stump. Those who did not like to look at their stump usually tried to hide it by wearing pants. In a phenomenological study by Sjödahl et al. [29], individuals who had an amputation also felt they needed to hide their amputated leg.
Functional independence increased with time and the coping strategies associated with this type of adjustment changed according to setting. During hospitalization (T1), accepting responsibility and seeking social support were positively associated with functional independence, while positive appraisal and planful problem solving were associated only in the home setting (T3). The same pattern of change was found in our study for strategies negatively linked to functional independence. Confrontive coping was related to lower levels of functional autonomy during hospitalization (T1), while escape-avoidance strategies were negatively associated with levels of functional autonomy during rehabilitation (T2) and after discharge (T3). Emotion-focused strategies have been linked to negative functional adjustment in other studies $[11,12]$, but our results also showed that during hospitalization, accepting responsibility was positively associated with functional independence. This divergence may be due to the fact that those other studies did not evaluate coping strategies in the first two weeks following the amputation.

4.1. Strengths and Limitations of the Study. A mixed-method design is particularly helpful in studying coping strategies because it gives a general picture of the situation that can be compared with other populations as well providing specific information on how individuals who had an amputation use those coping strategies. Qualitative methodology provides the opportunity to discover unexpected aspects of the events. In addition, collecting data specific to the hospitalization phase and focusing specifically on amputation due to vascular disease generated new information about these specific contexts that have rarely been explored in the amputation literature.

However, the study had a number of limitations that need to be discussed. The decision to collect data at three different points in time introduced biases linked to the loss of participants. Five of the initial participants (24\%) were not reevaluated at $\mathrm{T} 3$. However, none of the participants involved in the qualitative part of the study dropped out at any point in time. Individuals who refused to participate did not differ significantly from the participants on most variables, except that men were more likely to exclude themselves from the study.

Additionally, participants were recruited in a single acute care university hospital. Consequently, we cannot assume that they are representatives of all individuals who had a lower limb amputation. Finally, the relatively small sample size has an impact on the ability to detect real associations (power) and the internal validity of the results. Despite the study's limitations, the findings provide new information concerning the coping strategies used to deal with lower limb amputation and their relationship to adjustment in three different settings.

\section{Conclusion}

The results of this study reflect the inherented complexity of coping with a lower limb amputation and its variability 
across the different settings encountered within the first few months following the amputation. Future research should be conducted on a larger sample, using a mixed-method approach to uncover a large diversity of coping efforts used, by individuals who had a lower limb amputation. It is important to develop knowledge not just about which strategies are used but also how they are used, and if they promote positive adjustment and in which context. This type of information is crucial to support the efforts of people with amputation and the work of health care professionals.

\section{Acknowledgments}

This research was supported by the Canadian Institutes of Health Research, the Fonds de la Recherché en Santé du Québec, and the Québec Rehabilitation Research Network that granted doctoral research awards to the first author. Special thanks are due to all the participants and the health care workers who facilitated data collection procedures. The authors would like to express thier deepest gratitude to Dr. Chantal Caron, researcher at the Research Center on Aging in Sherbrooke, Québec (Canada), for her vital contribution to this study. Right up to her death in January 2009, she continued to work on and sustain this project in remarkable fashion.

\section{References}

[1] M. A. Hanley, M. P. Jensen, D. M. Ehde, A. J. Hoffman, D. R. Patterson, and L. R. Robinson, "Psychosocial predictors of long-term adjustment to lower-limb amputation and phantom limb pain," Disability and Rehabilitation, vol. 26, no. 1415, pp. 882-893, 2004.

[2] R. Ham, J. De Trafford, and C. Van De Ven, "Patterns of recovery for lower limb amputation," Clinical Rehabilitation, vol. 8, no. 4, pp. 320-328, 1994.

[3] C. D. Murray and J. Fox, "Body image and prosthesis satisfaction in the lower limb amputee," Disability and Rehabilitation, vol. 24, no. 17, pp. 925-931, 2002.

[4] J. M. Behel, B. Rybarczyk, T. R. Elliott, J. J. Nicholas, and D. Nyenhuis, "The role of perceived vulnerability in adjustment to lower extremity amputation: a preliminary investigation," Rehabilitation Psychology, vol. 47, no. 1, pp. 92-105, 2002.

[5] C. Bodenheimer, A. J. Kerrigan, S. L. Garber, and T. N. Monga, "Sexuality in persons with lower extremity amputations," Disability and Rehabilitation, vol. 22, no. 9, pp. 409-415, 2000.

[6] O. Uzun, C. Yildiz, A. Ates, A. Cansever, and A. S. Atesalp, "Depression in men with traumatic lower part amputation: a comparison to men with surgical lower part amputation," Military Medicine, vol. 168, no. 2, pp. 106-109, 2003.

[7] L. Coffey, P. Gallagher, O. Horgan, D. Desmond, and M. MacLachlan, "Psychosocial adjustment to diabetes-related lower limb amputation," Diabetic Medicine, vol. 26, no. 10, pp. 1063-1067, 2009.

[8] L. F. Phelps, R. M. Williams, K. A. Raichle, A. P. Turner, and D. M. Ehde, "The importance of cognitive processing to adjustment in the 1st year following amputation," Rehabilitation Psychology, vol. 53, no. 1, pp. 28-38, 2008.

[9] G. M. Williamson, R. Schulz, M. W. Bridges, and A. M. Behan, "Social and psychological factors in adjustment to limb amputation," Journal of Social Behavior and Personality, vol. 9, no. 5, pp. 249-268, 1994.

[10] M. S. Pinzur, F. Littooy, J. Daniels et al., "Multidisciplinary preoperative assessment and late function in dysvascular amputees," Clinical Orthopaedics and Related Research, no. 281, pp. 239-243, 1992.

[11] A. Hill, C. A. Niven, and C. Knussen, "The role of coping in adjustment to phantom limb pain," Pain, vol. 62, no. 1, pp. 79-86, 1995.

[12] A. Whyte and L. J. Carroll, "The relationship between catastrophizing and disability in amputees experiencing phantom pain," Disability and Rehabilitation, vol. 26, no. 11, pp. 649654, 2004.

[13] H. Livneh, R. F. Antonak, and J. Gerhardt, "Psychosocial adaptation to amputation: the role of sociodemographic variables, disability-related factors and coping strategies," International Journal of Rehabilitation Research, vol. 22, no. 1, pp. 21-31, 1999.

[14] P. Gallagher and M. MacLachlan, "Psychological adjustment and coping in adults with prosthetic limbs," Behavioral Medicine, vol. 25, no. 3, pp. 117-124, 1999.

[15] D. M. Desmond and M. MacLachlan, "Coping strategies as predictors of psychosocial adaptation in a sample of elderly veterans with acquired lower limb amputations," Social Science and Medicine, vol. 62, no. 1, pp. 208-216, 2006.

[16] R. S. Lazarus, "Coping theory and research: past, present, and future," Psychosomatic Medicine, vol. 55, no. 3, pp. 234-247, 1993.

[17] E. L. Teng and H. C. Chui, "The Modified Mini-Mental State (MMS) examination,” Journal of Clinical Psychiatry, vol. 48, no. 8, pp. 314-318, 1987.

[18] G. Bravo and R. Hébert, "Age- and education-specific reference values for the mini-mental and modified mini-mental state examinations derived from a non-demented elderly population," International Journal of Geriatric Psychiatry, vol. 12, no. 10, pp. 1008-1018, 1997.

[19] S. Folkman and R. S. Lazarus, Ways of Coping Questionnaire, Consulting Psychologist Press, Palo Alto, Ca, USA, 1988.

[20] P. P. Vitaliano, R. D. Maiuro, J. Russo, and J. Becker, "Raw versus relative scores in the assessment of coping strategies," Journal of Behavioral Medicine, vol. 10, no. 1, pp. 1-18, 1987.

[21] A. T. Beck, C. H. Ward, M. Mendelson, J. Mock, and J. Erbraugh, "An inventory for measuring depression," Archives of general psychiatry, vol. 4, pp. 561-571, 1961.

[22] D. Gallagher, G. Nies, and L. W. Thompson, "Reliability of the Beck Depression Inventory with older adults," Journal of Consulting and Clinical Psychology, vol. 50, no. 1, pp. 152-153, 1982.

[23] M. Bruchon-Schweitzer, "Dimensionality of the body-image: the body-image questionnaire," Perceptual and Motor Skills, vol. 65, pp. 887-892, 1987.

[24] M. Koleck, M. Bruchon-Schweitzer, F. Cousson-Gélie, J. Gilliard, and B. Quintard, "The body-image questionnaire: an extension," Perceptual and Motor Skills, vol. 94, no. 1, pp. 189196, 2002.

[25] R. Hébert, R. Carrier, and A. Bilodeau, "Le système de mesure de l'utonomie fonctionnelle (SMAF)," La Revue de Gériatrie, vol. 13, pp. 161-167, 1988.

[26] J. Desrosiers, G. Bravo, R. Hebert, and N. Dubuc, "Reliability of the revised functional autonomy measurement system (SMAF) for epidemiological research," Age and Ageing, vol. 24, no. 5, pp. 402-406, 1995.

[27] M. B. Miles and M. A. Huberman, Qualitative Data Analysis: An Expanded Sourcebook, Sage, London, UK, 1994. 
[28] R. S. Lazarus and S. Folkman, Stress, Appraisal and Coping, Springer, New York, NY, USA, 1984.

[29] C. Sjödahl, G. Gard, and G. B. Jarnlo, "Coping after transfemoral amputation due to trauma or tumour-a phenomenological approach," Disability and Rehabilitation, vol. 26, no. 14-15, pp. 851-861, 2004.

[30] K. Oaksford, N. Frude, and R. Cuddihy, "Positive coping and stress-related psychological growth following lower limb amputation," Rehabilitation Psychology, vol. 50, no. 3, pp. 266277, 2005.

[31] B. Rybarczyk, J. J. Nicholas, and D. L. Nyenhuis, "Coping with a leg amputation: integrating research and clinical practice," Rehabilitation Psychology, vol. 42, no. 3, pp. 241-255, 1997.

[32] D. Zidarov, B. Swaine, and C. Gauthier-Gagnon, "Quality of life of persons with lower-limb amputation during rehabilitation and at 3-month follow-up," Archives of Physical Medicine and Rehabilitation, vol. 90, no. 4, pp. 634-645, 2009. 


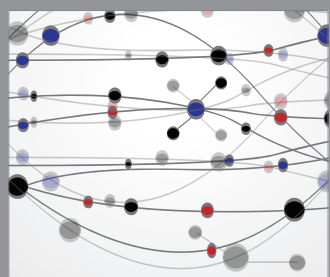

The Scientific World Journal
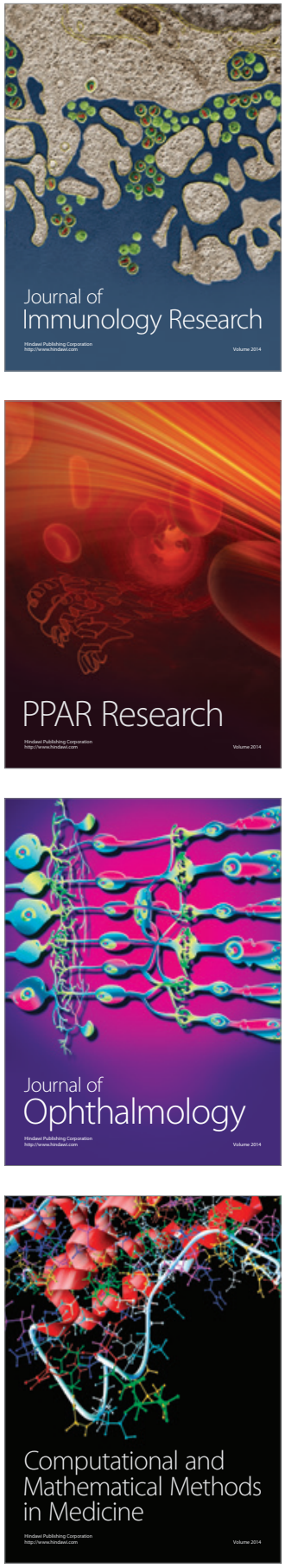

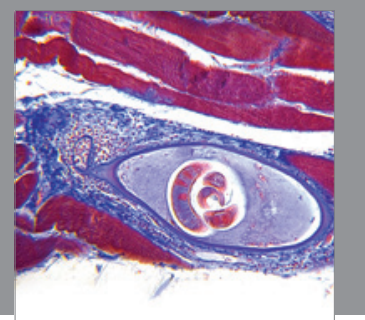

Gastroenterology

Research and Practice
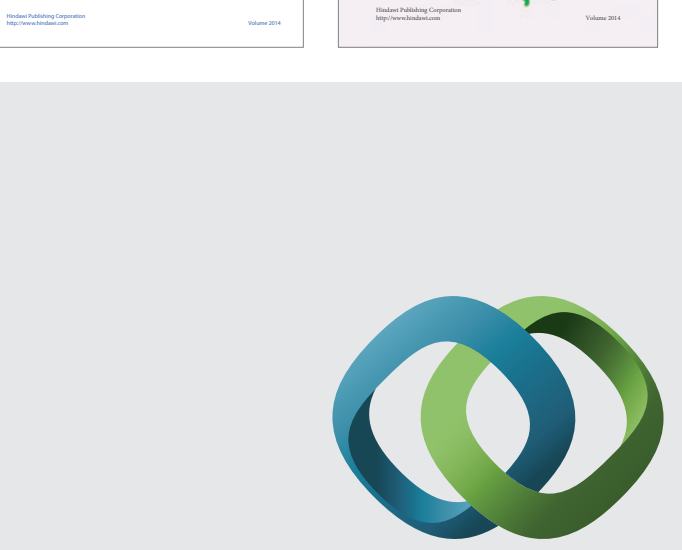

\section{Hindawi}

Submit your manuscripts at

http://www.hindawi.com
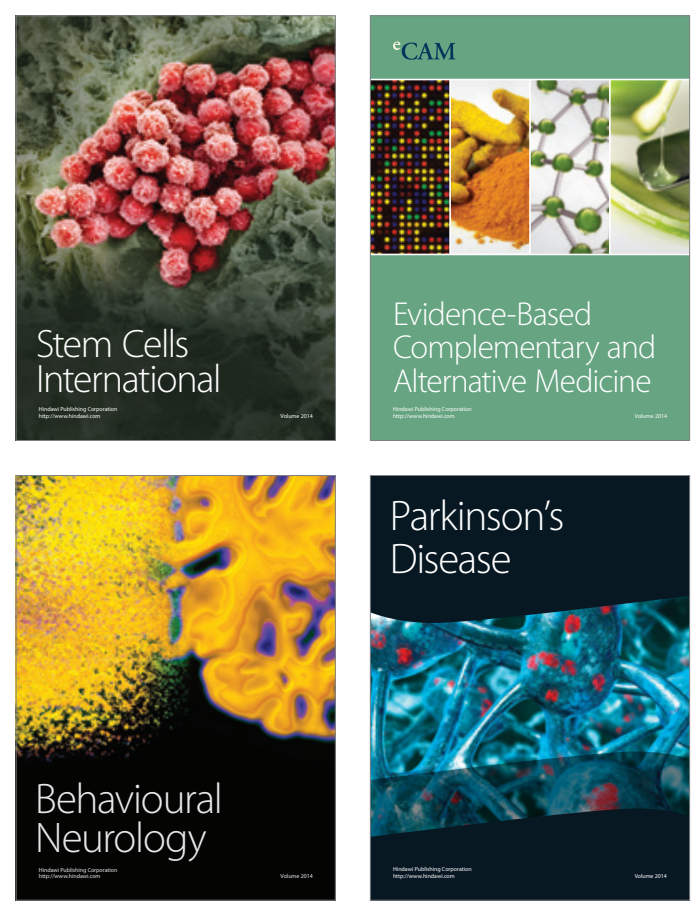

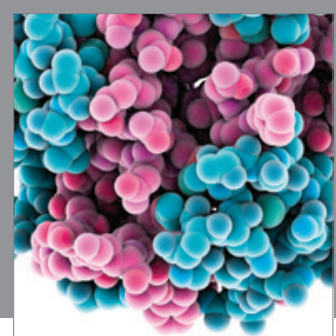

Journal of
Diabetes Research

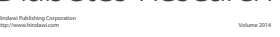

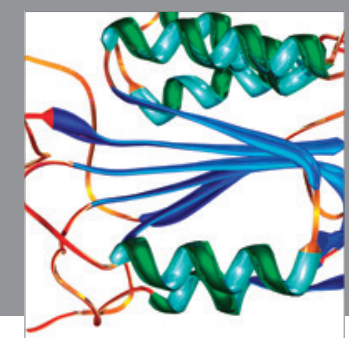

Disease Markers
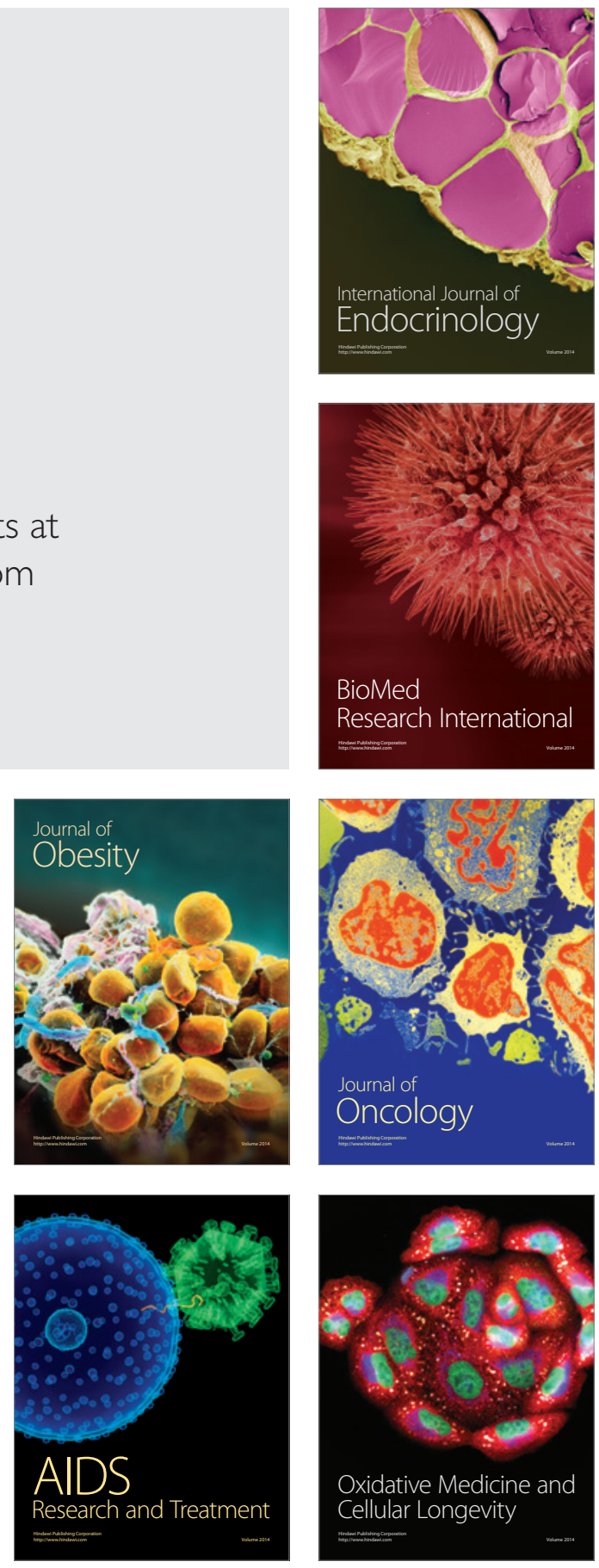